\title{
Corrigendum to "Consumers' behavior in quantitative microbial risk assessment for pathogens in raw milk: Incorporation of the likelihood of consumption as a function of storage time and temperature" (J. Dairy Sci. 99:1029-1038)
}

\section{Matteo Crotta, Franco Paterlini, Rita Rizzi, and Javier Guitian}

There was an error in equation [2] (page 1031); the denominator should read $1+e^{\alpha+\beta_{1} T^{\circ}+\beta_{2} h}$. The corrected equation is

$$
\operatorname{logit}^{-1}\left(p_{i}\right)=\frac{e^{\alpha+\beta_{1} T^{\circ}+\beta_{2} h}}{1+e^{\alpha+\beta_{1} T^{\circ}+\beta_{2} h}}
$$

The same equation error occurs in Figure 1 (page 1032); the corrected figure is shown below.

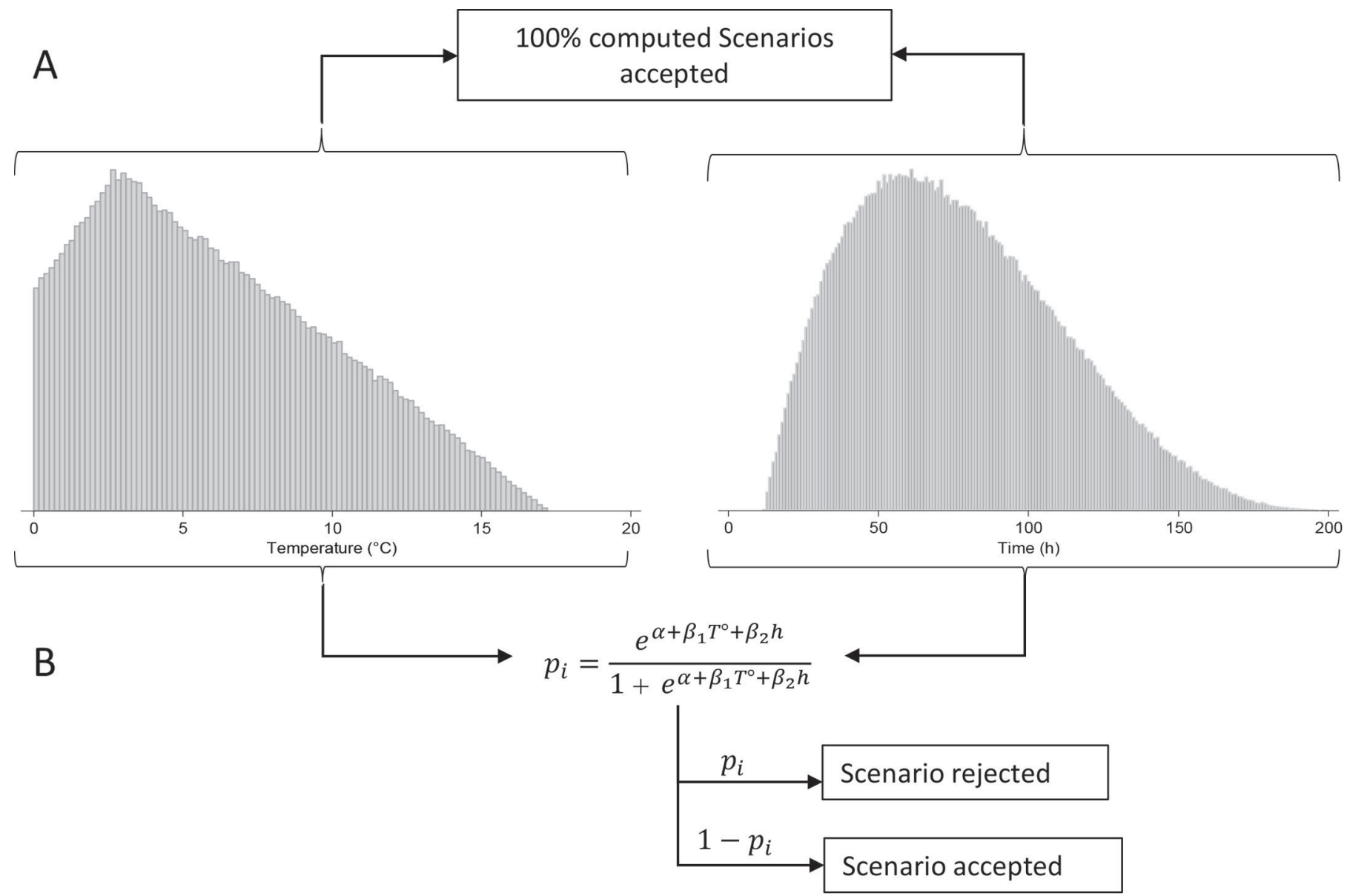

Figure 1. Distributions describing the storage time and temperature assumed by Latorre et al. (2011) in quantitative microbial risk assessment related to risk of listeriosis due to raw milk in the United States. (A) In the original model all time-temperature combinations can yield a serving that could be consumed. (B) Inclusion of Equation 2 implies that at any time-temperature combination, the milk has a certain probability $\left(p_{i}\right)$ to be recognized as spoiled by the consumer and thus not actually consumed. $T^{\circ}=$ temperature; $h=$ time; $\alpha, \beta_{1}$, and $\beta_{2}=$ the constant terms obtained by the multiple regression model. 
In Table 3 (page 1033), the independent variables Time $(\mathrm{h})$ and Temperature $\left({ }^{\circ} \mathrm{C}\right)$ were reversed. The corrected table is shown below, with corrected values in bold.

The authors regret the errors.

Table 3. Coefficients of multiple logistic regression models for the association between the probability of raw milk being recognized as spoiled and the storage time-temperature combination ${ }^{1}$

\begin{tabular}{llccc}
\hline Equation & Independent variable & Coefficient & $2.5 \%$ & $97.5 \%$ \\
\hline $\mathbf{A}^{\mathbf{2}}$ & Constant & -12.273 & 14.150 & 10.395 \\
& Temperature $\left({ }^{\circ} \mathbf{C}\right)$ & $\mathbf{0 . 4 8 8 3}$ & $\mathbf{0 . 4 0 3}$ & $\mathbf{0 . 5 7 3}$ \\
$\mathbf{B}$ & Time $(\mathbf{h})$ & $\mathbf{0 . 0 6 6 1}$ & $\mathbf{0 . 0 5 4}$ & $\mathbf{0 . 0 7 8}$ \\
& Constant & -13.004 & 15.025 & 10.983 \\
& Temperature $\left({ }^{\circ} \mathbf{C}\right)$ & $\mathbf{0 . 5 1 6 1}$ & $\mathbf{0 . 4 2 6}$ & $\mathbf{0 . 6 0 6}$ \\
& Time $(\mathbf{h})$ & $\mathbf{0 . 0 7 1 8}$ & $\mathbf{0 . 0 5 8}$ & $\mathbf{0 . 0 8 5}$ \\
\hline
\end{tabular}

${ }^{1}$ The regression curves were fitted to data from the evaluation of 30 samples of milk stored at different timetemperature combinations by 2 panelists. Results of each panelist (A and B) are reported independently.

${ }^{2}$ The equation coefficients were selected to be included in quantitative microbial risk assessment.

\section{REFERENCES}

Crotta, M., F. Paterlini, R. Rizzi, and J. Guitian. 2016. Consumers' behavior in quantitative microbial risk assessment for pathogens in raw milk: Incorporation of the likelihood of consumption as a function of storage time and temperature. J. Dairy Sci. 99(2):1029-1038. 10.3168/ jds.2015-10175. 